\title{
Post-Disaster Counselling: Personal, Professional, and Ethical Issues
}

\author{
Abstract \\ This paper examines the experiences of specialist volunteer mental health counsellors \\ establishing and managing an early intervention service. This research investigates \\ personal, professional and ethical issues faced by volunteer counsellors following the \\ 2011 earthquakes in the Canterbury region of New Zealand. Earthquakes create \\ major community disruption resulting in scarce resources requiring new agency \\ arrangements and increased use of volunteers to manage and provide \\ services. Volunteer counsellors working with the Canterbury Charity Hospital were \\ interviewed about the personal, professional, and ethical issues they faced in \\ providing early intervention services. The earthquake exposed counsellors to \\ personal challenges in their own lives as well as those of their clients and significantly \\ affected their professional practice. The findings indicate that emergency \\ organizations and professional registration bodies should give further consideration to \\ the management of volunteers and their early intervention work in post-disaster \\ counselling.
}

\section{Implications}

- Delivery of post disaster services must encompass service management, targeted interventions and supervision.

- When counsellors and clients experience the same disaster personal, professional and ethical aspects are intertwined. Counsellors need self-care and support to manage these events.

- Further enhancement of professional insurance is sought for volunteer counsellors post disaster. 


\section{Introduction}

In February 2011 Christchurch in the Canterbury area suffered a large earthquake resulting in loss of life, major infrastructure damage, and disruption of community and social services. Earthquakes are rarely one solitary event but rather a succession of major and minor aftershocks that continue for a sustained period resulting in unrelenting stress and anxiety.

Immediately following a disaster, normal civil arrangements are replaced by a command and control structure with legal powers in the hands of key emergency personnel. Delivery of psychosocial services is changed. Personnel are scarce and agencies may be relocated to temporary accommodation without familiar technological or administrative support. Staff may be working with a new group of colleagues or working with lay volunteers using practice models for emergencies such as psychological first aid (Australian Red Cross 2013) or using specialist personnel in either a voluntary or paid capacity (North Atlantic Treaty Organization [NATO] 2008). With this level of fragmentation, scarcity and uncertainty, it is not surprising that personal, professional ethical problems emerge in the delivery of services.

\section{The personal experience}

Psychosocial problems post disaster include threat to life, exposure to injured people and disfigured bodies from traumatic injuries, bereavement, loss, disruption to housing, schooling, unemployment, and hardship (NATO 2008, S1-32). Individuals respond with various reactions depending on the phase of the disaster (Tyhurst, 1957), and pre-existing risk factors such as childhood abuse, life stresses or lack of social support (Alexander, 2005).

Citizens respond with resilience to disasters despite the potential to become distressed (NATO, 2008, S.1-34). There is increasing understanding of the emotional responses counsellors experience when exposed to trauma (Campbell, 2007).

Counsellors are often stressed by secondary trauma as they listen to their clients' trauma narratives (Tosone, Nuttman-Shwartz, \& Stephens, 2012).

The personal and the professional are not discrete in fraught situations. Research on counsellor experience refers to "shared trauma" or "double exposure" (Baum, 2010, 2012a, 2014; Dekel, Nuttman-Shwartz, \& Lavi, 2016; Saakvitne, 
2002). Both provider and client experience the same event. Sharing may arguably impact on the counsellors' personal, professional, and ethical domains. The term 'double exposure', (Baum 2012a, 2014) applies to counsellors working in areas with sustained exposure to danger whilst simultaneously responding to the psychosocial needs of people in their communities. Baum (2012a, 2014) examined the experiences of counsellors working in war zones with people exposed to similar situations. Features of this double exposure included intrusive anxiety about personal and family safety and concerns that they were unable to do their job. In the response phase of disasters, many professionals in double exposure situations immerse themselves in their professional roles, actively seeking voluntary opportunities.

Baum (2010) argued that practitioners working in traumatogenic environments are deprived of the benefits of clinical distance and distinct boundaries. They are neither able to escape nor remove themselves from the environment. Tosone et al. (2012) discussed the experiences of clinicians exposed to similar trauma as their clients. Although the personal and professional mesh in shared trauma, clinicians note positive outcomes. "Shared trauma affords clinicians the opportunity for personal and professional growth as well as heightened intimacy in the therapeutic environment" (Tosone et al., 2012, p. 237).

\section{Professional Issues}

Professional issues are practice matters arising in the agency context. Specific matters are determined by agency characteristics and services provided, the professional mandate, and the policy and jurisdictional frameworks. Many regulatory, funding and professional bodies and employers have specified practice expectations which include supervision, recording, and interpersonal communication requirements. There are also tacit professional expectations, such as resilience, flexibility, intuitiveness, and astuteness (Manning, Miller, Newton, \& Webb, 2007). Situation specific factors post disaster may preclude or override standard professional expectations creating tensions and challenges in service delivery (Van Heugten 2014).

Disasters cause great destruction to physical infrastructure including health and welfare delivery systems (Milner, 2013). Van Heugten (2014) reminds us that human service workers are first on the scene and continue their work long after front line emergency workers depart. Services, personnel, and structures existing before the destructive event may not function afterwards. Specialist services may take time 
to re-establish or may be irrelevant in the situation. Management of professionals post-disaster, professional roles, approaches to interventions, referrals, prioritisation, allocation of cases to staff, professional development, and supervision may take on a different complexion. Many of these issues may easily be overlooked in the turmoil.

Core principles for post-disaster service delivery are discussed in numerous reports including Stanke, Murray, Amlôt, Nurse, \& Williams (2012), and NATO (2008). In mental health services these include comprehensive evidence-based accessible services that are stepped and coordinated with other services; take account of and support "at risk"' diverse populations; and are delivered by a competent workforce.

A number of researchers have discussed paid practitioner roles and responsibilities post-disaster (Araki, 2013; Du Plooy, Harms, Muir, Martin, \& Ingliss, 2014; Manning et al., 2007; Yanay \& Benjamin, 2014). Any discussion of these roles must take account of the cultural context, the nature of the disaster, the service context, worker remuneration and the experience of agencies in service provision. Common elements include counselling, social assistance, crisis intervention, solutionbased therapeutic approaches, advocacy, mediation, problem-solving, and cross sector collaboration. Important roles for counsellors may be operationalising new or emergency services, managing day-to-day interventions with necessary systems and structures or social development strategies (Du Plooy et al., 2014; Hickson \& Lehmann, 2014; van Heugten, 2014). Many research discussions noted a simultaneous commitment to community engagement and empowerment in both short-term and longer-term delivery (Du Plooy et al., 2014; Hickson \& Lehmann, 2014; Javadian, 2007; Manning et al., 2007).

Researchers from the Asia Pacific region noted the importance of personal characteristics in working post disaster commenting that not every disaster worker has the necessary personal attributes. Important personal characteristics include a willingness to deal with the unexpected (Yanay and Benjamin 2005); resilience and energy (Manning et al. 2007); and capacity to respond to chaotic workplaces (Hickson and Lehmann 2014).

Self-care, teamwork, team communication and debriefings, sharing experiences with colleagues and supervision are strategies used to deal with personal stresses critical to staff management (Du Plooy et al., 2014). Some authors noted that agencies overlooked the personal needs of staff, ignoring the personal and emotional 
consequences of constant threats. They expected staff to commit firstly to agency services and come to work despite concerns about their family's safety (Baum, 2012a). Training in disaster management, disaster counselling and service delivery is a neglected aspect of professional education (Javadian, 2007; Sim, Ki, Quen, \& Dong, 2013). Hickson and Lehmann (2014) note the need for greater preparation for all staff who may be responsible for disaster management.

\section{Ethical Issues}

Ethical principles are embedded in humanitarian actions post-disaster (International Federation of Red Cross and Red Crescent Societies, http://www.ifrc.org/en/what-wedo/disaster-management/responding/ethics-in-disaster-response/. Services are provided without discrimination and with the aim of not doing further harm. Attention is given to vulnerable populations ensuring that basic human needs are met respectfully. Professional workers are guided by the principles and standards of behaviour outlined in their specific Codes of Ethics (Geale, 2012).

In disaster situations, increased demand for human services often necessitates difficult and complex decisions about allocation of resources and prioritisation of clients. These decisions often create dilemmas for practitioners. Whilst human service workers make every effort to enact professional values in practice, there are times when managers adopt a semi-military approach where ethical issues may not be understood or are overlooked (van Heugten, 2014, p. 139). Van Heugten noted that human service workers were most distressed when they lost control of decisionmaking, resulting in further trauma for clients.

Professional relationships with clients differ from personal relationships and are based on trust, safety, respect, and therapeutic intimacy. These limits protect clients and provide a safe environment for therapeutic practice (Baum, 2010). Many authors provide examples of boundary crossing including accepting and receiving gifts from clients, hugs and kisses at beginning and end of sessions, personal or business relationships outside the therapeutic environment, and disclosure of personal information to the client. In normal practice, these matters are regarded as serious legal and ethical infringements boundary violations being precluded with sanctions for transgressions.

Boundary issues during disasters are more complex. Researchers investigating double exposure (Baum, 2014) acknowledged the blurred boundaries 
between practitioners and clients when both have been exposed to the same event. Social workers working in disaster situations have recognised specific ethical challenges that include managing their patients' privacy whilst responding to the media and other citizens (Du Plooy et al., 2014; Manning et al., 2007).

\section{The Current Study}

The aim of this study was to investigate key challenges and decision making issues associated with developing and implementing an early intervention counselling service following the Christchurch earthquake in 2011. The paper examines a neglected dimension of counselling practice post-disaster: the personal, professional, and ethical practice experiences of a group of volunteer counsellors in early mental health intervention. It provides an appreciation of service management and delivery in the context of damage to and destruction of community infrastructure.

\section{Method}

\section{Research design}

As recovery from disasters is a complex phenomenon located in unique social contexts, a qualitative approach was chosen allowing exploration of both organisational change processes necessary for provision of a professional counselling service and the reflections of the volunteer professionals providing this service.

\section{Sample}

The focus of this research was the Canterbury Charity Hospital Trust (Charity Hospital) as the site of an early intervention service. Volunteer counsellors including social workers, nurses, psychologists, and accredited counsellors, came together to provide an emergency service in response to the earthquake. Insights into their personal, professional, and ethical issues in service delivery post-disaster allow us to learn from their experiences and informed us how to better manage complex issues in delivering mental health early intervention services in future disasters.

Following ethics approval by the University of Wollongong and the New Zealand Ethics Committee, the researchers sent a letter to administrative staff and professional volunteers working at the Charity Hospital after the 2011 earthquake inviting them to participate in the study. Contact was made using an email list the hospital had used to recruit professionals to work in the planned service. From a total 
of 56 emails sent, 17 responded saying they were willing to participate. Two members of the Hospital's Executive Management team also agreed to be interviewed. Nineteen professionals participated.

\section{Instrument}

A semi-structured interview format was used to interview the 19 volunteer professionals. Part one of the interview included questions about the participants' demographics and part two asked questions that explored their work in the Charity Hospital, how referrals were made to the agency, interventions used, personal and professional challenges encountered, interagency work, who they considered the most vulnerable populations, professional practice issues, and general questions about disaster management and community recovery.

\section{Data Collection}

Fourteen research interviews were held at the Charity Hospital, two participants were interviewed in their homes at their request, and three who had left the city were interviewed via SKYPE. Each interview began with a brief summary about the study and informed consent obtained. Permission to record the session was signed. All were advised that participation was voluntary and that they had the right to withdraw their consent at any time.

The interviews were recorded electronically and in the hard copy on the semistructured interview sheets. Later, they were transcribed by an independent transcription service. All identifying information was removed before transcription to protect the participants' anonymity. Transcripts were sent to each participant for verification of accuracy before being entered into data analysis.

\section{Data Analysis}

Interview data were analysed using thematic coding, a method well established for use in such studies (Denzin, 1994). The codes were then used to describe common themes emerging from the interviews. Measuring quality in qualitative research is a contentious issue, with diverse opinions and various frameworks available within the evidence base (Reilly \& Parker, 2012, p. 190). To address this issue, two of the researchers individually coded participant responses, which were later recoded into themes. A third researcher then examined the transcripts and thematic analysis 
undertaken by the first two researchers. All three researchers closely agreed on these themes. Qualitative questions asked during interviews included many practice-related challenges faced in counselling and counsellors' specific personal concerns arising in their day-to-day practice.

\section{Results}

\section{Demographic data}

There were 19 participants. Female counsellors dominated with 68\% women and $32 \%$ men. Table 1 shows that all counsellors were over 30 years of age with $10 \%$ over 70. Forty-two percent of counsellors were in the 50 to 69 years bracket and all were experienced holding senior positions or in private practice. All practitioners held tertiary qualifications in social work, nursing, medicine, psychology and counselling and were legally registered.

\section{Insert Table 1 here.}

\section{Emergent themes}

The qualitative analysis identified seven themes coming from three broader areas, personal, professional and ethical.

Personal themes identified included indelible emotions from the destruction and personal impact of the earthquake, the associated emotional vulnerability, challenge of loss, the new normal and a different way of existing.

Professional themes included managing the post disaster volunteer workforce, recognizing that working in earthquake trauma is different and the feeling that volunteers were flying by the seat of their pants highlights the need for supervision especially self-care and support and were all professional themes.

Ethical themes included a duty to assist in a crisis.

\section{Personal}

\section{Indelible emotions}

All counsellors discussed their personal earthquake stories with researchers, including damage to their home, loss of community and neighbourhood and getting to safety. They also discussed experiences of counselling during the aftershocks. During one session the counsellor reported that she and client rolled across the room and back 
again during an aftershock. One therapist, trapped at the epicentre, lying in the rubble, heard voices saying, "It's not your time" and, a bit louder, "Move!" Some tried to make sense of the situation: "I guess the biggest issue was doing something [counselling] at the same time as making sense of the earthquake . . it was surreal and took a lot of energy . . . to get to grips with what was happening." Others noted the sense of vulnerability and loss: "The quakes leave an indelible mark on our very being ... we have lost something we can never retrieve ... it is a numbness."

\section{Emotional vulnerability}

During the earthquakes and aftershocks, there was a lot of loud noise; sounds described as if large trucks were close. Aftershocks occurred at any time of the day or night including during counselling sessions with clients, requiring both parties to seek safety. Others mentioned being startled by any loud noise. They regarded this as a normal response as the thousands of aftershocks were heralded by loud noises. Earthquakes and shocks created anxiety for everyone, and some refused to enter buildings. Other therapists linked the earthquakes with personal distress including in two cases the death of family members, although not as a result of the earthquake. One counsellor stated, "the exposure to horror stories of the earthquake resulted in . . . your body is on high alert and exhaustion as a result of that. This exposure continued for another two years."

\section{The challenge of loss}

Many practitioners experienced loss of individual or family income from employment. In travelling to the Charity Hospital for sessions, most counsellors struggled with the damage to the city's infrastructure (no ATM), particularly blocked roads and missing signposts.

Many buildings in the inner city housing private counselling practices were severely damaged. Several counsellors spoke about loss of business income from their private practice post-earthquake. Clinicians unable to return to their practices found time to work as volunteers: "My therapy rooms were damaged . . . and the usual clients were not coming after the February quake. . . . I did not have a specific place of work. . . I had time to help." A school counsellor said, "The school wasn't there." Another said she was volunteering because her husband had lost his job and was able to stay at home and look after the children. 


\section{The new normal: a different way of living}

The earthquake and aftershocks meant a "different way of living" as described by a social worker participant. Many with damage to their homes spoke of the inconvenience of this damage, and of frustrating discussions with insurance companies regarding repairs. At the time of the interviews (four years postearthquake), some participants still had no repairs done.

Two participants discussed changes in their personal habits including sleeping with a torch beside the bed in case of another quake overnight. One practitioner born overseas described having to be mindful of keeping her important personal identification, bank documents and papers with her at all times in case her home was destroyed. Others talked about being vigilant and checking exits in unfamiliar buildings, especially those buildings described as rabbit warrens. This is not dissimilar to the war zone experiences of social workers in Israel (Baum, 2012a).

Counsellors' experiences of ongoing aftershocks impacted on the therapeutic process at many levels. Reactions to the earthquake were common and not abnormal, this being used effectively in counselling to normalise experiences. Practitioners learnt from clients, emergency workers, and other health professionals about ways of coping. Counsellors reflected on various client coping strategies noting that "personal stress was compartmentalised and that they were coping with a stressful work environment and personal stress as well”.

Most practitioners valued the opportunity to help the Charity Hospital. "Doing the counselling work actually helped me get through the earthquakes because it gave me a focus for other people, to help other people. My partner was struggling with the earthquakes, and he wanted to up sticks and go [elsewhere]." Being aware of the personal impact of earthquake stories was necessary. "Taking on less of the dramatic stuff" was a necessary decision by some workers.

\section{Professional}

Mobilizing the post-disaster volunteer workforce

The first task of the newly established early intervention mental health service was recruitment of professional volunteer counsellors willing provide a new service. Participants wanted to use their skills to contribute to mental health and community recovery, but finding avenues to do so was difficult for some. Many were recruited 
through local counsellor networks by "word of mouth" and able to provide immediate assistance. Others wanted to use their skills but had trouble locating an agency where they could make a valuable contribution. One counsellor commented that as none of the professional bodies were organised to assist the recruitment process, he initially started volunteering with the Salvation Army and the Red Cross at the local recovery centre. "Just being there was useful and he wanted to make sure that the staff who were doing the caring for others were cared for." Other counsellors contacted their GPs who connected them to the Charity Hospital, with some social workers referred by the ANZASW after involvement in local volunteering.

Volunteer counsellors were not remunerated for their contribution to the Charity Hospital. Some volunteered only for the Charity Hospital while others maintained full-time work in addition to voluntary counselling. Very few retired clinicians assisted, as they were no longer registered and there were no mechanisms for them to assist. Not surprisingly, practitioners asked questions about the best way to mobilise a skilled professional workforce post-disaster.

All counsellors who worked at the Charity Hospital were registered with their professional association and presentation of qualifications was a requirement for volunteering. For most counsellors, the registration body was in New Zealand, but for three, their professional bodies were in the USA or the UK. Neither the counsellors nor the agency knew if their registration, legal protection, and indemnity insurance were valid outside their home environment. The use of their professional title was a similar concern. Other practitioners registered in New Zealand were not aware if their professional insurance or the agency's insurance covered them for working in a voluntary capacity. Only one counsellor had checked with their registration board before commencing volunteering.

\section{Working in earthquake trauma is different}

Approaches to practice reflected the counselling experiences and diversity of professional backgrounds. Therapy sessions were supported by written material referred to as psychoeducation, generally focusing on normalising emotional reactions, giving hope, and managing anxiety. Practice was eclectic and pragmatic, generally in single sessions, with focused condensed assessments. Cognitive strategies were regularly used as therapeutic strategies. Many practitioners noted their lack of expertise in disaster counselling and commented on differences between 
standard counselling practice and practice post-earthquake. One respondent experienced in trauma counselling mentioned "that trauma counselling is useful but working in earthquake trauma is very different to trauma counselling in practice.” The workers felt they were dealing with anxiety, grief and practical assistance. Client needs ranged from those who had lost everything to those who were minimally impacted by the disaster. Some questioned the value of trauma work and its therapeutic application to disasters. Many thought disaster counselling was a specialist area of practice that should be a required part of professional courses.

\section{Flying by the seat of our pants}

The counselling service was started from scratch immediately after the earthquake. Whilst the Charity Hospital had experience in managing hospital admissions and surgical services, this did not extend to developing and providing early intervention mental health counselling services. One participant said: "We were flying by the seat of our pants and felt as if we were starting a new job without any training."

Counsellors identified the importance of effective service management for successful early intervention mental health service. In the pre-disaster context, service management is taken for granted. Common concerns included specifying the type of agency service; advertising the service with local GPs; helping clients without transport to access the service using a voluntary taxi service; processes for making and accepting referrals; developing appropriate files and systems to record information within the context of a regulated health service; and a system for indexing and specification of policies and procedures. The overall success of the program may be attributed to skilled management.

A particular concern was that workers had no background information about the clients. There were no agency records; doctors were swamped with crisis work and their written referral information was often brief without a current history or presenting problem. Many counsellors raised questions about prioritisation of services. Referral to other services could not occur as many specialized mental health services were not operational, and it was difficult to locate or contact practical assistance given the system disruption. When counsellors had concerns about their clients' mental health, they raised the matter with on-site medical staff and obtained advice, medication, and specialist referrals. There was little time to develop and use 
team strength. A constant concern was that some serious issues might be missed given the brevity of practice contact and inadequate time to do full assessments.

\section{Self care and support}

All counsellors were mindful of the importance of self-care and support in regular supervision. There were no supervision sessions initially, but senior practitioners were always on hand to talk to counsellors after their sessions. These discussions were consultative and supportive in orientation. After several weeks, regular supervision was established, although many private practitioners maintained their previous supervisory arrangements outside the agency.

\section{Ethical issues}

\section{A duty to help}

The number of ethical issues identified was not surprisingly large although many issues were common to all counsellors. Commitment to assist others and a duty to help people in a time of crisis were very explicit. Many worked nine to five in their paid positions and held after-hours sessions at the Charity Hospital. "I have a duty to help people through it . . . if you can't be there in a crisis what sort of [professional] are you?"

Counsellors and clients shared the common experience of the earthquake and aftershocks and this was raised in the opening conversation. Counsellors did not interpret discussing their shared experiences of the earthquake as an ethical violation. Clients appreciated being 'understood' without a detailed explanation. Counsellors regarded the shared experiences as a way of building rapport whilst maintaining therapeutic control.

Boundary issues were mentioned, but there were different and contradictory perspectives. Many referred to registration requirements which they strictly interpreted. One counsellor was very explicit that boundaries between worker and client were fixed irrespective of the practice situation or emergency. Another counsellor commented that a client was looking for a ride home, a reasonable concern given challenges with navigation around the city and the absence of public transport. She said, "This was a time when boundaries may have been transgressed." Another therapist said, "I have done it all my life. I gave a mother and children a lift down to the shops and did not think anything of it." 
Privacy was a major difficulty. Counsellors saw clients in private rooms or spaces which were often sometimes operating theatres, recovery rooms, consulting rooms, or a shipping container adapted for this purpose. Counsellors acknowledged that these rooms were not ideal but were practical under the circumstances. The media did not intrude seeking stories. Consent for transfer of a counselling report back to GPs was discussed with clients. Seeking consent for private information to be given to referral agencies was not regarded as a serious problem as there were so few operational agencies. Counsellors were aware of colleagues' upheaval. As Christchurch is not a large city, therapists recognised particular names on referrals and were concerned that they might be referred a friend or family member.

\section{Discussion}

Counsellors' experiences post disaster revealed challenges in managing their personal emotional vulnerability associated with the earthquake and personal losses of home and neighbourhood and the similar experiences of clients. Counsellors had been recruited to a new service where they developed new ways of intervening post disaster. Managing this new service posed challenges for counsellors including organizing and delivering services, dealing with a professional regulatory environment, providing supervision and support and responding to ethical issues especially negotiating professional boundaries arising in practice.

The personal and professional are closely linked. At the Charity Hospital, clients and counsellors shared their earthquake experience and its aftermath. Counsellors listened to client stories and experienced double exposure and shared trauma (Baum 2014). Given the unpredictability of aftershocks, it was inevitable that clients and counsellors jointly experienced uncertainty during sessions. The therapeutic process included some discussion of the shared experiences of clients and workers enabling engagement (Baum 2012a) but it was not the focus of the session.

Shared experiences meant that counsellors were deprived of clinical distance (Baum 2010). From a professional viewpoint, managing professional boundaries (Du Plooy et al (2014) was challenging but explicit. The common experience of the earthquake made it difficult for all to navigate. Counsellors used the experience of the earthquake and the resulting emotional response to normalize the emotional and behavioural impact on clients and for themselves. It was as if the emotional responses 
were not abnormal but a perfectly reasonable emotional response in the context (Baum 2010).

Practitioners implicitly assume that practice management systems are in place, although issues abound (van Heugten, 2014). This was not the situation at the beginning of the Charity Hospital service, with systems being established on the run. There are standards covering professional requirements for files, patient consent, referral to specialist services, and adaption to a new way of practising. Supervision and self-care arrangements were not available initially but were within a short time.

Psychological first aid is the starting point for support post-disaster (Australian Red Cross 2013), but evidence-based interventions at the next level of service are not specified or evaluated. Counsellors immediately recognized deficiencies in direct application of trauma counselling practice in early interventions post disaster and commenced new interventions using the core service principles for a stepped mental health service (see Stanke et al., 2012; NATO, 2008). These interventions were not evaluated.

All counsellors indicated that it was helpful to be involved in a voluntary experience and all spoke highly of the service provided by the Charity Hospital (Tosone et al., 2012). This differs from other research where paid workers rather than specialist volunteers were the participants (Manning et al 2007; DePlooy et al 2014; Tosone et al 2012). In Baum's (2014) study workers resented the pressure and expectations exerted by their employers during the war. This study didn't explore why involvement was helpful or the extent to which it provided a long-term benefit to counsellors.

Apart from Israeli literature (e.g., Baum, 2012, 2014) on social workers' responses to war, it is assumed that counsellors are "outsiders" brought in to provide assistance to the local community (Manning et al., 2007; Du Plooy et al., 2014). Outsider perceptions of management of counselling differ from insider experiences and practice approaches as evident in the work of Manning et al. (2007) and Du Plooy et al. (2014). Manning et al. (2007) discussing off shore deployment advocated working for a team, three-week rotations, preparation and equipment of suitable staff, access to resources, and a communications infrastructure. This is not possible for insider volunteers. Supervision, debriefing, and documentation of learning were all necessary and provided. 
This disaster in New Zealand affected all citizens, agencies and professions. Findings from this research suggest lessons for and conversations within professional bodies, policy makers, registration boards, and governments, disaster recruitment of professionals. It also suggests the need for thoughtful approaches to service delivery at the point of the disaster to later phases of recovery.

\section{Limitations}

Nineteen out of 56 counsellors responded to an interview. These interviews allowed exploration of the complexities of post disaster practice. It is not known if these views and the researchers' interpretations accurately represent commentary about disaster counselling practice. The extent to which this study can be extrapolated to other disaster situations is not known as the policy, economic and professional regulatory environments may be very different. Despite these limitations, this study illustrates innovative service delivery and a rapid response to emerging needs.

\section{Conclusion}

Disasters are not normal events and have a profound impact on counsellors' personal and professional lives. Counsellors are exposed to both their own trauma and that of their clients. It is timely to consider the implications of this research for education in professional programs and continuing education and for stepped service delivery models post-disaster. Future research in this area might assist conceptualising disaster counselling for those exposed to the disaster and those coming from the outside to assist and both paid and specialist volunteers.

\section{References}

Australian Red Cross. (2013). Psychological First Aid. Retrieved from https://www.redcross.org.au/getmedia/23276bd8-a627-48fe-87c2$\underline{\text { 5bc6b6b61 eec/Psychological-First-Aid-An-Australian-Guide.pdf.aspx }}$

Alexander, D. A. (2005). Early mental health intervention after disasters. Advances in Psychiatric Treatment, 11, 12-18.

Baum, N. (2010). Shared traumatic reality in communal disasters: Toward a conceptualization. Psychotherapy: Theory, Research, Practice, Training, 47(2), 249-259. 
Baum, N. (2012a). "Emergency routine": The shared experience of professionals in a shared traumatic reality of war. British Journal of Social Work, 42, 424-442.

Baum, N. (2012b). Trap of conflicting needs: Helping professionals in the wake of a shared traumatic reality. Clinical Social Work Journal, 40, 37-45.

Baum, N. (2014). Professionals' double exposure in the shared traumatic reality of wartime: Contributions to professional growth and stress. British Journal of Social Work, 44, 2113-2134.

Baum, N. (2016). Secondary traumatization in mental health professionals: A systematic review of gender findings. Trauma, Violence and Abuse, 17(2), 221-235.

Campbell, L. (2007). Utilizing compassion fatigue in Hurricanes Ivan and Katrina. Clinical Social Work Journal, 35, 165-171.

Dekel, R., \& Baum, N. (2009). Interventions in a shared traumatic reality: A new challenge for social workers. British Journal of Social Work, 40(6), 19271944.

Dekel, R., Nuttman-Shwartz, O., \& Lavi, T. (2016). Shared traumatic reality and boundary theory: How mental health professionals cope with the home/work conflict during continuous security threats. Journal of Couple and Relationship Therapy, 15, 121-134.

Denzin, N. (1994). The art and politics of interpretation. In N. Denzin \& Y. Lincoln (Eds.), Handbook of qualitative research (pp. 500-515). London: Sage.

Du Plooy, L., Harms, L., Muir, K., Martin, B., \& Ingliss, S. (2014). "Black Saturday” and its aftermath: Reflecting on postdisaster social work interventions in an Australian Trauma Hospital. Australian Social Work, 67(2), 274-284.

Geale, S. K. (2012). The ethics of disaster management. Disaster Prevention and Management: An International Journal, 21(4), 445-462.

Harms, L. (2015). Understanding Trauma and Resilience. London, Palgrave.

Hickson, H., \& Lehmann, J. (2014). Exploring social workers' experiences of working with bushfire-affected families. Australian Social Work, 67(2), 256273.

Javadian, R. (2007). Social work responses to earthquake disasters: A social work intervention in Bam, Iran. International Social Work, 50, 334-346. 
Manning, C., Miller, S., Newton, T., \& Webb, S. (2007). After the wave: The Centrelink social work response offshore. Journal of Social Work in Disability and Rehabilitation, 5(3-4), 81-95.

Milner, V. (2013). In the zone: Keeping hope alive through shaky times. Aotearoa, New Zealand Social Work, 25, 45-57.

North Atlantic Treaty Organization (NATO). (2008). Psychosocial care for people affected by disasters and major incidents: A model for designing, delivering and managing psychosocial services for people involved in major incidents, conflict, disasters and terrorism. Retrieved from https://www.coe.int/t/dg4/majorhazards/ressources/virtuallibrary/materials/Ot hers/NATO_Guidance_Psychosocial_Care_for_People_Affected_by_Disaster s_and_Major_Incidents.pdf

Nicholls, P. (2017). Christchurch earthquake map. Retrieved from http://www.christchurchquakemap.co.nz/largest

Nuttman-Shwartz, O. (2015). Shared resilience in a traumatic reality: A new concept for trauma workers exposed to personally and professionally to collective disaster. Trauma, Violence and Abuse, 16(4), 466-475.

O’Reilly, M., \& Kiyimba, K. )2015 .(Advanced Qualitative Research: A Guide to Using Theory. London: Sage.

O’Reilly, M., \& Parker, N. (2012). “Unsatisfactory saturation”: A critical exploration of the notion of saturated sample sizes in qualitative research. Qualitative Research, 13(2), 190-197. Doi:10.1177/1468794112446106.

Saakvitne, K. W. (2002). Shared trauma: The therapist's increased vulnerability. Psychoanalytic Dialogues, 12(3), 443-449.

Sim, T., Ki, A. Y. W., Quen, C. H., \& Dong, Q. H. (2013). Rising to the occasion: Disaster social work in China. International Social Work, 56, 544-562.

Soliman, H. H., \& Rogge, M. E. (2002). Ethical considerations in disaster services: A social work perspective. Electronic Journal of Social Work, 1(1), 1-23.

Stanke, C., Murray, V., Amlôt, R., Nurse, J., \& Williams, R. (2012). The effects of flooding on mental health: Outcomes and recommendations from a review of the literature. Retrieved 17 January 2017 from https://www.ncbi.nlm.nih.gov/pmc/articles/PMC3461973/

Tosone, C., Nuttman-Shwartz, O., \& Stephens, T. (2012). Shared trauma: When professional is personal. Clinical Social Work Journal, 40, 231-239. 
Tyhurst, J. S. (1957). Psychological and social aspects of civilian disaster. Canadian Medical Association Journal, 76, 385-393.

van Heugten, K. (2014). Human service organizations in the disaster context. Houndsmills, England: Palgrave Macmillan.

Yanay, U., \& Benjamin, S. (2005). The role of social workers in disasters: The Jerusalem experience. International Social Work, 48, 263-276. 
Table 1: Respondent's characteristics $(\mathrm{N}=19)$

\begin{tabular}{|l|l|l|}
\hline & N & $\%$ \\
\hline Gender & 13 & 68 \\
Female & 6 & 32 \\
Male & & \\
\hline Age Groups & & \\
30-49 years & 5 & 26 \\
$50-69$ years & 8 & 42 \\
70 plus & 2 & 11 \\
Not stated & 4 & 21 \\
& & \\
\hline Profession & & \\
Counsellor & 6 & 31 \\
Doctor & 2 & 11 \\
Nurse & 2 & 11 \\
Psychologist & 5 & 26 \\
Social Work & 4 & 21 \\
& & \\
\hline
\end{tabular}

